\title{
Internationalization Tool for the U.S. Universities
}

Prof. José Carlos Quadrado P.E., ISEP-Instituto Superior de Engenharia do Porto 
2017 ASEE GLOBAL COLLOQUIUM - Internationalization Tool for the US Universities

José Carlos Quadrado - ISEP

Norman Fortenberry - ASEE

The 2017 ASEE Global Colloquium (GC2017) was held September 16-18 in Terceira, Azores, Portugal. The host institution was the Instituto Superior de Engenharia do Porto (ISEP). The event was held immediately before the SEFI Annual Meeting in the same location.

Following the several challenges for the US attendees in participating in the GC2017, the agenda of the event was refashioned to increase the engagement and leverage the expertise of those present. While searching for international exposure as a common target for all the participants, due to the final layout of the event it was possible to summarize the issues of interest to them. The issues were collapsed eventually into four main interest domains, namely: Adapting to New Digital Students; Competency-based Engineering Education; Games for Learning; and Mathematics in the Engineering Curriculum.

The GC2017 was deemed successful by the participants however several questions arise about the ASEE community perception of the event importance as an internationalization tool for the US universities. 